\title{
The Geological-Evolutional Concept of Resin Genesis
}

\author{
Maksym A. Bogdasarov ${ }^{1}$ and Georgii I. Rudko ${ }^{2}$ \\ 1. Department of Geography and Nature Management, Faculty of Geography, Brest State A.S. Pushkin University, 21, Kosmonavtov \\ Boulevard, 224016, Brest, the Republic of Belarus
}

2. The State Commission of Ukraine on Mineral Resources, 18/7 Kutuzov St., off. 816, 01133, Kyiv, Ukraine

\begin{abstract}
Geological and evolutionary concept of the genesis of fossil resins: Fossil resins are a special group of natural organic compounds. The work is devoted to the determination of special features of formation, distribution, properties, composition of different types of fossil resins. The paper deals with the evolution of concepts of origin of fossil resins, contains data on the sources of resiniferous vegetation, discusses a problem of succinosis and a role of the chemical impact of mineral medium containing resins on the process of their formation, substantiates prospects of revealing of new resin deposits in the Mesozoic and Cainozoic sedimentations of Northern Eurasia.
\end{abstract}

Key words: Fossil resins, resin genesis, phytogeographical areas, succinosis, rumänite, gedanite, retinite.

\section{Introduction}

Proceeding to the discussion of a problem of fossil resin genesis it should be noted that for more than 130 years, starting from G. Geppert's publication [1], a variety of work has been devoted to this subject, and none of them could answer completely a whole range of questions relating to botanical belonging of resiniferous plants, reasons of succinosis, peculiarities of galipot fossilization and its transformation into resin, a species diversity of fossil resins, conditions for accumulation of resins and formation of their considerable accumulations and, at last, a place of fossil resins in the classification of natural non-crystalline formations.

The reasons thereof seem to us quite obvious. First, at the beginning of scientific research of fossil resins (19th-the first half of the 20th century) almost all knowledge of them was based on the data only on succinite and material collected mainly in the Baltic

Corresponding author: Georgii I. Rudko, Doctor of Geological and Mineralogical Sciences, Doctor of Geographical Sciences, Doctor of Technical Sciences, professor, research fields: geology of mineral deposits, engineering geology, medical geology, geomorphology, environmental geology, geoecology, economic geology. region, and, secondly, a level of development of science did not enable to conduct the analytics feasible at the current stage. Speaking about the last third of the 20 th early 21 st century a whole number of serious scientific works devoted to fossil resins of both the Baltic and other regions should be certainly noted [2-9].

The obtained data have considerably pushed specialists forward in understanding of the reasons and mechanisms of resin formation. However, the issues on genesis of this type of raw materials are still debatable that is connected, on the one hand, with the fact that many authors adhere to the pre-existing conceptual notions developing their various aspects out of any connection with a huge array of new analytical data, and, on the other hand, the majority of scientific achievements in the field of study of fossil resins have been made by narrow specialists-physicists and chemists who are interested only in certain aspects of this problem and who do not even set themselves the purposes which geologists are guided by as an object.

\section{Materials and methods}

Fossil resins take a certain place in the system of classification of carbonaceous minerals. Very 
noticeable connection of present-day resins with fossil resins leaves no doubts as to their vegetable origin, and, in our opinion, a way of transformation of galipot of plants of former geological epochs into mineral bodies defined now as fossil resins should be mainly determined by post-sedimentation processes. A chemical nature of the majority of resins predetermines their big stability in comparison with other classes of substances composing a vegetable organism. This stability allows resins to change a little at a complex of transformations which sphacelated vegetable material that has been experiencing during long periods. While lignin and cellulose being a part of wood turn into humic substances in the course of time and give rise to formation of the bulk of coal, some fossil resins keep even small parts of their internal structure.

It is quite clear that the study of fossil resins shall be based on the data obtained at study of similar modern formations and carried out by the same physical and chemical methods. At the same time it is necessary to remember that even exact definition of "resin" is a rather complex problem. The properties of substances relating to natural resins turn out to be so different that determination of physical properties and establishment of chemical composition not always give sufficiently reliable attributes for the inclusion of one or another substance in the group of resins. Solution of the problem of genesis of these unique natural formations is based on the consecutive consideration of all stages of transformation of pine pitch into fossil resins and formation of their accumulations.

The property common for all resins is not their chemical structure or any physical constants, but their origin. Resins represent excretes (secretions) of plants, apparently, not participating in the vital processes of a vegetable organism after their formation. In fact, resins in a live plant turn out to be diluted to a greater or lesser extent with essential oils forming galipot. As noted above, the plants being a source of galipot, on the basis of which resins appeared, belonged mainly to coniferous plants. The reservation is required only for a part of resins connected with Paleozoic coals [10] and originates from the most ancient representatives of gymnosperms such as cordaites.

The author's research provided in the work [9] enables certainly to confirm a vegetable nature of all representatives of fossil resins, but further revealing of their botanical belonging and division of resins into groups by this attribute is rather difficult. Complexity consists in that the carried out investigations of galipot of present-day conifers ( 9 species) have not given a definite answer to this question though there was an effort to look into possible vegetable communities the formation of studied types of resins was connected with. By using V. S. Trofimov's materials [11] and own data, the author has compared all known resin finds with the fields of distribution of floristic communities of the Cretaceous-Paleogene epoch (Fig. 1).

\section{Results}

Analysis of available data has shown that with rare exception almost all resins are found to occur within two major phytogeographical areas-coniferous and broad-leaved forests of temperate humid and warm climate (the Turgai flora) and deciduous and evergreen vegetation of subtropical climate (the Poltava flora). Apparently, formation of fossil resins was a natural phenomenon in evolution of flora of our planet caused by the largest change of the vegetable cover in the Aptian-Albian [11]. This change and onset of a new stage of flora development-Kainophyt affected fast distribution of angiosperms, appearance of a new formation of conifers and disappearance of a number of ferny, cicada, sago, bennettitales and other forms of vegetation of the Mesophyte.

Two consecutive phases can be determined in the Kainophyt. The first one covers the Upper Cretaceous-Paleocene and is characterized by poorly expressed climatic and botanical-geographical zoning. There was no clear boundary between the areas of coniferous and broad-leaved forests of warm temperate climate and subtropical deciduous and evergreen vegetation. 


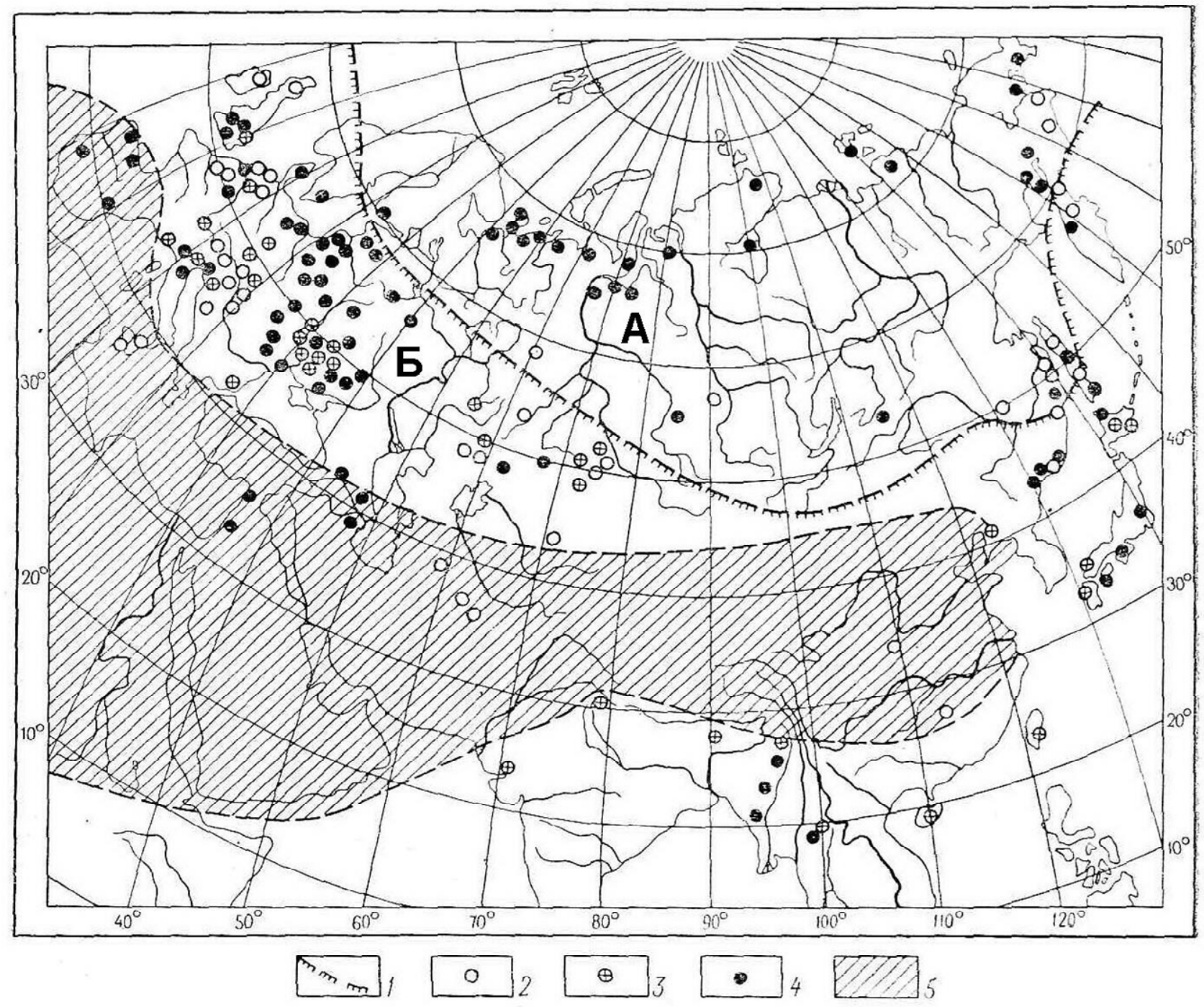

Fig. 1 The scheme of distribution of phytogeographical areas (the Upper Cretaceous-Eocene) and points of fossil resin finds in Eurasia according to V. S. Trofimov [11] and added by the author: (1) boundary of the area of coniferous and broad-leaved forests of warm temperate climate (A) and the area of deciduous and evergreen forests of subtropical climate (Б); (2) sites of floristic residue finds; (3) sites of finds of palm tree residues of subtropical climate; (4) sites of fossil resin finds; (5) area of arid climate and xerophilous vegetation.

Judging by the finds of plant fragments and inclusions of insects in resins [11], it is possible to assert that formation of the latter has been spatially and genetically connected with vegetation of the stated areas.

The second phase of the Kainophyt started from the Eocene. Climatic and botanical-geographical zoning was expressed rather clearly in it. In the second phase of the Kainophyt the areas of distribution of fossil resins were narrowed and kept apart, resin formation became less intensive than in the Cretaceous period, but still remained as there were no essential changes in the composition of vegetation connected with the appearance of new forms. By the end of the Oligocene resin formation decreased greatly in connection with the fall of temperature in the territory under consideration.

From the middle of the Cretaceous and up to the end of the Oligocene within the phytogeographical areas of Northern Eurasia there was more or less one-type 
vegetation, therefore, to define certain areas differing drastically from each other in botanical communities was almost impossible. Besides not all fossil resins can be compared with galipots of present-day conifers to identify features of their similarity and difference as initial chemical peculiarities of resins are kept only in certain exceptional cases.

The work [12] systematizes research results of the chemical composition of galipots of conifers growing in the territory of Northern Eurasia, considers composition, structure and properties of terpenoids of thirty species of conifers, and gives chemotaxonomic characteristics of conifers under genera and species. Upon careful analyzing information contained in this work and comparing the available resin research results with it, we have come to a conclusion of certain similarity between galipot composition of the genus Pinus, subgenus Strobus (Haploxylon), section Strobus and resins of the retinite group that to a certain extent corresponds to Larsson's opinion [13].

Even now there is no common opinion concerning the reasons of abundant exudation of resin by conifers that is afterwards transformed into fossil resins. For quite a long time the Konvents' [14] hypothesis explaining the abundant pine resin exudation with adverse conditions of their growth has enjoyed the popularity. However, the detailed study of a present-day resin-bearing property of conifers [15] has shown that intensive tree wounds, especially forest fires, damage their water supply and reduce galipot exudation. Resin production by plants depends not on damages being only a necessary condition for galipot exudation, but on individual properties of trees and conditions of their growth. It has been clearly established that weakness of plants is a result of intensive resin exudation, but not vice versa. Weakened trees are usually underproductive, and they are the first to become a victim of wreckers. Therefore, from our point of view, Konvents' [14] theory explains not the reasons of high resin productivity of "amber" conifers, but only the reasons of resin exudation.
Productivity depends on a whole set of physiological processes occurring in a tree the failure of which can lead either to drastic increase or reduction of galipot exudation [15]. It should be emphasized that galipot exudation of present-day conifers increases gradually to the south reaching the maximum on the very border of the area of growth. Besides, some species of conifers of the tropical belt (Agathis australis) have a high resin-bearing property (certain pieces of galipot reach $20 \mathrm{~kg}$ ).

Another factor, the resin productivity of conifers depends on, humidity of their habitat. It is well known that galipot exudation increases in the wet weather as pressure in the resin ducts changes depending on humidity. However, excessive humidity affects negatively the productivity of trees. The weak galipot exudation under conditions of constant excessive moistening is explained by the fact that the sizes of a trunk and a root system decrease greatly, and though the number of resin ducts increases, but the osmotic pressure does not change in them [15]. Therefore, in our opinion, optimum air and soil humidity for conifers is a first-priority condition for increase in galipot exudation. Air and soil temperature, and also development of a crown and a diameter of a trunk have a great impact on the productivity of trees therefore it can be stated that a high galipot exudation of "amber" conifers depended mainly on favorable conditions of their growth.

A number of researchers point to climate warming in the Eocene. According to Kaptarenko-Chernousova [16] it is known that the Kiev period (the middle Eocene) was warmer in comparison with the Buchakian one preceding it and the subsequent Kharkovian one. Baranov [17] noted that Eocene flora of Europe testified to sharp warming of the climate and its bigger humidity. Based on this data Katinas [3] explained the emergence of increased resin exudation of conifers in connection with climate warming.

Scrupulous analysis of data on paleogeography of the period of formation of resin-bearing sediments in 
Northern Eurasia given in the works $[9,18]$ enables to tell about the greatest plausibility of wrongly forgotten Bachofen-Echt's conclusions [19] who connected huge quantities of resin with the duration of process of its exudation and a big area of "amber" forests.

According to paleobotanic data given in the work [9] the most plausible assumption is that fossil resins were formed in warm, humid climate. Specific forests, where the thermophilic conifers abundantly producing galipot under conditions of warm wet subtropical close to tropical climate dominated, covered big territories. Galipot of these trees as a result of influence of many geological factors provides a basis for formation of primary (basement) resin deposits gradually washed away in the shallow-water coastal zone of sea basins in the territory of the Eurasian regions considered above.

Resin formation is a natural process which cannot be connected with any extreme factors, for example, climatic events (a cold snap, tropical hurricanes, forest fires), geological events (forest flooding with sea waters, adverse influence of soil solutions), peculiar biological conditions (damage to trees by different insects, parasitic plants and fungi). Though all these phenomena could really take place it is impossible to agree with such explanations of the reasons of succinosis as conifers grew under absolutely normal living conditions and a galipot exudation corresponded completely with rather favorable conditions of their habitat. Makarenko [20] notes absolutely justly that intensive development of animal and vegetable communities is possible only under conditions favorable for this purpose and reminds that formation of shell stone, chalk, marble, dinosaur cemeteries is caused not by bad, but favorable living conditions for the existence of mollusks, coccolithophorids, blue-green algae and reptiles.

For our part, we consider that the normal resin-bearing system of fossil conifers could easily differ in increased diameters of resin ducts the finds of very big pieces of fossil resins testify to. Consequently, a little increased productivity was characteristic of them under normal conditions. Amber-bearing conifers grew in the area of high temperatures, in the zone of transition of evergreen subtropical vegetation to coniferous and broad-leaved one [21]. Resin exudation processes are natural processes of activity of trees, but not only conifers. These processes accompanying a tree life promoted formation of significant quantities of galipot at different times in many areas of the Earth. Damages to trees throughout their life can be caused by various reasons - activity of insects, birds, small rodents and bigger mammals, and also gale-force winds, lightning strokes, forest fires, sharp daily fluctuations in temperature. So it is possible to consider that all listed factors played an essential role in resin formation. But formation of large resin exudations of Northern Eurasia is connected not so much with the increased resin productivity of fossil conifers as with favorable facial situations of subsequent accumulation of resins, otherwise considerable resin accumulations could not be formed in the secondary bedding.

Some researchers [11, 22, 23] explain quite often all distinctions between mineral types of fossil resins by the differences in the real composition of initial galipot of plants they originated from, and only to an insignificant extent by the changes that galipot experienced in the course of fossilization and diagenesis. Based on the study of physical and chemical properties of fossil resins of Northern Eurasia, and also features of structure and composition of resin-bearing deposits carried out within the investigation [18] and having taken as a basis Savkevich's structures [2] performed in the course of his study of resins of the Baltic region, we will consider evidences testifying to the impact on galipot and resins of surrounding rocks, and also a set of factors which have promoted the formation of different types of resins.

In our opinion, a process of formation of fossil resins includes several consecutive stages. The first of them covers formation of galipot, its exudation from a tree, and also initial moments of fossilization on a daytime 
surface. Trees exude galipot often and intensively. Probably, it represented transparent light yellow low-viscosity fluid sometimes including cell sap. The surface changes in galipot occurring at a rather high temperature, free air access, influence of light evoked evaporation of volatile components, polycondensation and oxidation of resinous substances, isomerization of resin acids causing reduction of their variety and led to darkening, increase in density and finally to resin consolidation. Duration of the first stage was small and limited to the period of existence of a resin-yielding tree, i.e. to the first centuries.

Initial distinctions in the galipot composition predetermined, in particular, by different physiological and climatic factors are leveled quickly enough (within the species and even the genus) quite often even during lifetime of plants, including due to the processes of isomerization of resin acids. This conclusion is easily confirmed with the observation of changes happening to galipot of modern tropical plants transforming into copal [24].

At the second stage after the consolidated galipot gets into soil, its further transformations will depend on a situation with the environment-aerobic or anaerobic. In both cases at the beginning it will be exposed to the bacterial impact which leads to formation of thin (millimeter factions) dust taint (typical for investigated resins identified as gedanite) touching only a superficial part of the sample.

In aerobic conditions the processes of polycondensation and oxidation leading to the further changes of physical properties of resin will go on. It gradually gets darker shades of yellow color, gets covered with crust of oxidation with different power, its solidity increases, melting temperature increases, solubility in different solvents decreases. So, in the course of subaerial diagenesis thanks to the emergence of a number of additional oxygen bonds in the macromolecule, the formation of a spatial polymer skeleton in resin occurs the change in some of the listed properties of resins testifies to.
In anaerobic conditions characteristic, for example, of peatbogs, the processes of oxidation in resins stopped, and they underwent changes which, using Chirkh's [25] terminology, can be characterized as the processes of autoreduction. Then resin underwent changes caused by chemism of resin-containing sediments. The stated circumstances led to the emergence in such resins connected spatially and genetically with brown coal of a whole number of properties significantly differing them from resins formed in aerobic conditions - absence of the crust of oxidation, high brittleness, low melting temperature, high solubility.

The third stage in formation of the majority of resins is characterized by washout of primary surrounding rocks, transfer and deposition of resins in a new sedimentation basin that marks a change in the surrounding geochemical conditions. Katinas [3] considers transformations of resins at a final stage of their formation only as addition to the changes which took place in the soil of "amber" forest and in his opinion, added to resin its key characteristic properties. Let's consider another point of view stated by Savkevich [2], and show that his hypothesis is well confirmed by our data.

All finds of fossil resins diagnosed as amber (succinite) are connected with sandy-argillaceous rocks containing glauconite that testifies to the formation of these sediments in subaqual conditions. The presence of siderite and pyrite in the amber-containing rocks along with glauconite demonstrates intensive processes of diagenesis in them with glauconite being formed the first of authigenous minerals in the presence of oxygen in potassium-enriched sludge waters as evidenced by data on blue earth sections microscopically studied [26].

Amber permeability for fluids and gases, and also its ability to swell up in water gave grounds to Savkevich [27] to assert that properties of resin could be exposed to the impact of the environment existing in the sediment during its reburial. So, the sludge 
oxygen-containing and potassium-enriched waters interacted with resin in the alkaline medium and promoted a number of intra- and inter-molecular transformations in it which led to the formation of different oxy compounds and finally to the abstraction of free succinic acid. According to Chirkh [25], autoxidation processes (as well as oxygen redistribution in resins) flow intensively exactly in the alkaline medium, and especially in the presence of potassium.

At consideration of fossilization conditions leading to amber formation, attribution of succinic acid content in fossil resins to their occurrence among other rocks similar to the "blue earth" of the Baltic region under the conditions of diagenesis is of special interest. All types of studied resins characterized by the presence of succinic acid are also deposited among the rocks containing glauconite. Let us take Belarusian and Ukrainian resins as an example which are similar to succinite by their physical properties and chemical composition, contain succinic acid (5.62-7.11\%) and are deposited in glauconitic sands.

The above facts show that the formation of amber (succinite), i.e. chemical transformations of fossil galipot followed by the appearance of different oxygen compounds in it including succinic acid and its ethers in combination with the characteristic changes of physicochemical properties, occurs mainly at burial of oxidized resins in sediments with changeable oxidation-reduction conditions and alkaline medium. In unoxidized resins, the formation of which took place in the anaerobic environment before washout of their primary deposits, a set of absolutely different properties characteristic, for example, of gedanite and retinite was formed. And even despite the joint occurrence with succinite, similar properties of gedanite made by Orlov and Uspensky [28] relate it to a classification group of retinite. In sea water both succinite and other resins could be in similar geochemical conditions, but the impact of this environment on resins with another background was different.

The above data bring out clearly that the composition and properties of fossil resins have been determined not so much by their botanical belonging as by geological history that our research data on amino-acid composition of resin demonstrates visually.

It is very interesting to find out which combinations of conditions lead to the formation of other mineral types of resins differing from both succinite and resins of a retinite group. First of all, it is rumänite (and its analogs) being the only, except succinite, variety of resins of Northern Eurasia with rather high utilitarian potential.

Comparison of geological conditions of succinite and rumänite location shows that the former can be found only in the territory of the East European Platform while the latter can be observed in the areas of orogenesis where such factors as temperature and pressure have fully revealed themselves. This observation made by Savkevich [29] by the example of Ukraine has been evidenced in the studies $[9,18]$ enabling to establish the presence of rumänite in relevant geological conditions not only in the Ciscarpathian region (Verkhneye Sinevidnoye), but also in Transcaucasia (Aitag, Ani), the Primorye (Lypovtsy), on Sakhalin (Moneron, Nayba, Starodub) and in Japan (Kuji, Chōshi).

The study of fossil resins we diagnosed as rumänite showed the dominance of fractured transparent and less often smoke-colored samples, the surface of which was divided into polygons by the system of parallel cracks not leading, however, to sample destruction thanks to the above effect of "healing". In our opinion, the emergence of a system of such cracks is caused by tectonic stresses transmitted to resin through the rock as rumänite-containing sediments are often folded. If tectonic stresses were not really strong, and surrounding rocks are more plastic, rumänite had only traces of plastic deformation. As we have found out, fossil resins get from primary bedding to secondary accumulations being wholly consolidated and, 
therefore, they should crack during their transfer at blows on solid objects. But in this case the cracks will have casual orientation, and will not have traces of "healing". All amber-like resins have a stable polymer skeleton containing macromolecule fragments with a large number of degrees of freedom; these fragments are able to move in a resin sample, without breaking its integrity. Increased temperature and pressure promote mobility of a mobile part of fossil resin. Transfer of mobile components to microcavities, the existence of which is confirmed by electron microscopy, proves the process of artificial resin clarification at heating. This explains also the dominance of transparent and smoke-colored sorts of rumänite. At a rather high temperature mobile components not only filled microscopic cavities, but also exuded on the walls of microcracks causing their partial "healing".

Stresses arising in a polymer skeleton of resins as a result of migration of mobile fragments of a macromolecule and pressure of surrounding rocks provoked its restructuring. In resins experienced sufficient oxidation at a stage of diagenesis this restructuring was expressed in breakage of bonds such as -O-O- and revealing of a number of double bonds with the formation of additional linkages in a polymer molecule. In IR spectra of rumänite only insignificant number of double exocyclic bonds can be found, and the number of $-\mathrm{C}=\mathrm{CH}_{2}$ bonds are much lower than in succinite. Reduction in a number of such bonds in the macromolecular structure cannot be attributed to oxidation processes as the oxygen content in rumänite is almost always lower than in succinite. Rumänite represents, therefore, a succinite evolution product that is confirmed by the identity of DTA curves of these resins, noticeably smaller solubility of rumänite in organic solvents testifying to the presence of a bigger number of linkages in the macromolecule than in succinite and, lastly, a lesser content of succinic acid in comparison with succinite in products of dry rumänite distillation.

However in all listed above areas of rumänite distribution we have also diagnosed very brittle sorts of resins, the presence of which, at first sight, breaks a harmonious concept of rumänite genesis. This fact gave the right to the critics of Savkevich [30], mainly to Trofimov [23, 31], to dispute his assumptions. A large amount of analytical data in combination with the study of peculiarities of geological structure and history of formation of resin-bearing sedimentations in Eurasia being at our disposal enable to claim that joint occurrence of such different resins as rumänite and, for example, walchowite or resins of the retinite group does not contradict the above opinions. At the proved joint occurrence within one manifestation of succinite and gedanite, and also connection considered above between succinite and rumänite, it is quite natural to assume that having got into the described conditions of high pressures and temperatures, brittle resins like gedanite (as well as other brittle resins) changed, but the nature of these changes was another.

Resins that did not pass a certain stage of their development in aerobic conditions and, therefore, without enough oxygen bonds in the structure of a polymer skeleton, were not exposed to such restructuring which at increased temperature and pressure brought resins sufficiently oxidized at the second stage to the transformation into rumänite. It is proved by the large number of resins found with a rumänite-like type of IR spectrum in occurrences of Transcaucasia (Ani) and Sakhalin (Starodub) having, nevertheless, all attributes of brittle resins of a retinite group-high brittleness, low melting temperature, absence of succinic acid and good solubility in organic solvents.

So, distinctions in texture, structure, molecular composition and a number of physical properties between viscous and brittle resins of these regions depend not only on different intensity of manifestation of such agents of catagenesis as temperature and pressure, but also they are caused by distinctions in geochemical evolution of these resins at a stage of diagenesis. Having analyzed geological history of 
areas of rumänite distribution, it is possible to make a natural conclusion that rumänite is related only to the areas exposed to orogenesis during their geological development (at different periods of time) followed by increased temperature and pressure in rocks.

At last, different hypergene factors, first of all oxygen, make a noticeable influence on texture, structure and molecular composition of resins. Oxidation takes place both at contact with air oxygen and under the influence of water containing oxygen and other oxidizers. At hypergene oxidation of fossil resins oxygen adheres to the place of remained exocyclic double bonds, and also to $\mathrm{C}-\mathrm{N}$ and $\mathrm{C}-\mathrm{C}$ bonds by formation of peroxides and hydroperoxides. The changes of resins arisen at their hypergene oxidation are diagnosed according to determination of microhardness, a value of brittleness, DTA and IR spectrometry. Hypergene oxidation of succinite leads to change not only in its coloring, but also in composition (a content of oxygen increases, a total content of carbon and hydrogen decreases), a structure (the number decreases and a ratio of peripheral functional groups changes, a structure of spatial macromolecular skeleton evolves due to the increase in number of -O-O- bonds) and, as a consequence, resin properties (microhardness, specific weight and an index of refraction increases, a value of brittleness, and melting temperature decrease, luminescence parameters are corrected). Similar rumänite transformations lead to formation of schraufite as the comparison of its samples with the oxidized zone of rumänite samples shows [30].

A special case of transformation of fossil resins is their sulfurization at stages of diagenesis and/or catagenesis predetermining the emergence of resin types widely spread, for example, in the Lviv Region of Ukraine. The fact is that owing to a similar combination of geological conditions of fossilization the fossil resins of quite separate areas of the globe have an identical chemical structure and properties also attracts attention.
The described combination of different factors predetermining a chemical structure of fossil resins enables to explain the continuity in change of their structure, composition and properties. Hence, it follows as was rightly pointed out by Savkevich [30] that many predefined types of fossil resins represented to a certain degree extreme or intermediate members of transition rows which could be identified with mineral types having limits of variability different for specific cases.

Historically, in many places of location of fossil resins the authors describing them for the first time gave their names to resins. By the end of the 20 century literature knew more than 120 names of fossil resins the majority of which was identified in the second half of the 19th-the beginning of the $20^{\text {th }}$ century. It is obvious that dedication of local terms for amber-like resins of the Cretaceous-Paleogene period is inexpedient as the majority of resins are characterized according to single analyses. They often represent nothing but types of resins exposed to the processes of diagenesis, catagenesis or hypergenesis described in the work [9]. Similar piling up of terms unapproved for fossil resins based on small, often insignificant differences, first of all, in elemental chemical composition makes their study difficult, and does not give any idea of utilitarian potential of these resins.

Usually primary occurrences of resins are of small practical value. They can be found only in fossil soils of "amber" forests representing continental sandy-argillaceous formations with plant residues, peats. These sediments are changed to varying degrees and can be turned into sandstones and argillites with inter-layers of lignites and brown coals. It should be noted that primary resin occurrence in sandy-argillaceous sediments is not always obvious, and a number of manifestations are theoretically referred to primary ones [11, 32]. Primary accumulations of resins usually have uneven distribution and low content of a useful component in the form of small fragments that is characteristic of 
brittle resins known in lignites and brown coals. These manifestations belong generally to a biogenous sedimentary class, and they can be mainly found in Central Asia, Siberia and in the Far East in the coal fields where resins are observed in the coal lenses and layers depositing among sands and sandstones.

Secondary manifestations of resins can be mainly observed in the Baltic region, Belarus, Ukraine, and also in the Ciscarpathian Region, Transcaucasia, Western Siberia and on Sakhalin. These manifestations are formed under different geological conditions. Some of them are formed near basement accumulations (dealluvial and proluvial deposits). Much more often resins were transferred before burial to some distances or were even exposed to redeposition (alluvial, marine, limnoglacial deposits) [11, 32]. It is possible to single out two geological commercial types of alluvial manifestations - modern and ancient (buried) deposits.

Among resin accumulations relating to a type of modern ones, two subtypes-alluvial deposits and marine beach deposits are of certain practical value. Their commercial value is not very big. Alluvial deposits in connection with low density of fossil resins form seldom considerable accumulations. They can be formed only under specific conditions: in river tree entanglements; on the bottom of rivers containing accumulations of fragments of tree trunks and branches, large boulders and pebble that favours the appearance of turbulent water motions and subsequent sedimentation of resins weighed in water; on the low boggy floodplains covered with small shrubby vegetation flooded at river flooding during which resins brought by water are held with bush branches. In alluvium of modern rivers resins washed out from basement or re-deposited fields are known in many areas. In Ukraine, for example, they can be found in modern alluvium on the banks of the Dnieper River, near Berislav and Kakhovka (the Kherson Region), near Kremenchug (the Poltava Region), and also at the beds of other rivers (the Khorol River, the Samara River) [11].
Marine beach deposits are formed at washout (during storms) of fossil resin deposits located below sea level or at washout by rivers during high water of both primary and secondary manifestations located in their basins with the subsequent transfer of washout products to the sea coast. Resins getting into the environment of sea waves, ebbs and flows are spread by flows along the coast and are partially thrown out on it forming beach deposits widespread on the coasts of the Mediterranean Sea (island of Sicily), the Black Sea (the delta of the Danube River), the Baltic Sea (Denmark, Germany, Poland, Russia, Lithuania, Latvia), the Sea of Okhotsk and the Sea of Japan (Kamchatka, Sakhalin). Resin accumulations in beach deposits can sometimes reach considerable sizes.

Two subtypes - marine lagoon-delta and limnoglacial can be singled out of the manifestations relating to a type of ancient (buried) deposits. The ancient marine lagoon-delta deposits containing large resin resources (the Baltic region, Ukraine) are of the greatest value. Limnoglacial deposits are generally known in Germany and Poland. In the Quaternary glaciers when moving to the South plowed out resin-containing rocks and transferred them in the distal direction. Later on resins were carried with glacial waters to lakes where sometimes quite considerable accumulations occurred. The subsequent glaciers creased preformed limnoglacial deposits and moraine deposits in folds, sometimes with the formation of overthrust faults. Accumulations are of small industrial value.

It is necessary to admit that manifestations of fossil resins of many regions of Eurasia have been studied not enough, but available data enable to single out the most important features of conditions for their accumulation. Owing to low density $\left(1.0-1.1 \mathrm{~g} / \mathrm{cm}^{3}\right)$, high brittleness and small hardness, absolutely special conditions observed in nature in exceptional cases are required for concentration of fossil resins in the deposits that explains the rarity of formation of accumulations with the commercial content of resins. 
Analysis of zoning of granulometric composition of present-day deposits of the beaches of the Baltic, Barents and Black Seas [3] shows that at material density close to $1.0 \mathrm{~g} / \mathrm{cm}^{3}$ the largest aggregates which can be buried afterwards among sandy-pebble deposits are thrown out by waves at the biggest distance towards land. On the contrary, small fractions are carried away from the coast into the sea, frequently as suspension. As applied to the distribution of pieces of fossil resins their zonal accumulation can be observed on the sites of the beach distant from a coastal edge covered with water at strong roughness. The material washed away in the sea is accumulated at the depths of attenuation of wave disturbance.

Considering the above information and using data provided in the work [9] as well as obtained from literary sources as a basis for our constructions, we have compared the features of paleogeography of different epochs of resin accumulation within all regions explored.

Analyzing the acquired information it is possible to make a very important conclusion: large manifestations are formed practically always and everywhere either within the low coastal plain flooded from time to time with the sea or in a shallow-water shelf part of the sea basin adjacent to the land - a principled moment to pay attention when studying the accumulations of fossil resins.

Central and Eastern Europe, and also Transcaucasia, Sakhalin and, perhaps, Western Siberia are the most prospective from the point of view of their industrial development. They are characterized by widespread deposits containing viscous resins-succinite and rumänite. These regions are most fully studied and have manifestations which can become new suppliers of jewelry types of resins to the world market.

In our opinion, main distinctions between the deposits of stated regions, on the one hand, and accumulations of resins in Central Asia, the Khatanga and Ust'-Yeniseyskaya Depressions, the Far East, on the other hand, consist in the following. In the first case the accumulation of fossil resins in marine glauconitic deposits favoured a change in their properties acquiring attributes enabling to consider these resins as jewelry raw materials. Under the influence of the above processes such resins became less brittle, harder and were enriched with succinic acid. In the regions experienced folding afterwards, a part of resins was changed by their acquiring bigger hardness, flexibility and thermal stability.

In the second case amber-like resins are connected with deposits which do not contain glauconite and it means that they were not exposed to the transformation processes which took place, for example, in the Baltic region. Such resins have kept many "primary" features-considerable brittleness, smaller hardness, lack of succinic acid, another composition that can give more information for knowing of their botanical belonging, but, unfortunately, reduces sharply the utilitarian potential of resins. However, the manifestations of the Khatanga Depression represent a really unique group of deposits of near drift the study of which brings us closer to the establishment of a systematic position of maternal vegetation and age of certain manifestations.

\section{References}

[1] Goeppert, H. K., and Menge, A. 1883. Dir Flora des Bernsteins. Danzig, 128.

[2] Savkevich, S. S. 1970. Amber. L.: Nedra, 190.

[3] Katinas, V. I. 1971. Amber and Amber-Bearing Sediments in the Southern Baltic Region. Edition 20. Collection of Scientific Works, LitNIGRI., Vilnius, 150.

[4] Yushkin, N. P. 1973. Amber of the Arctic Regions. Edition 7. Preprint: Komi Branch of the Academy of Sciences of the USSR, Syktyvkar, 45.

[5] Srebrodolsky, B. I. 1984. Geological Structure and Regularities of Location of Amber Deposits in the USSR. Kiev: Naukova Dumka, 166.

[6] Matsuy, V. M., and Nesterovsky, V. A. 1995. Amber of Ukraine (A State of the Problem). Kiev: Terra, 56.

[7] Kosmowska-Ceranowicz, B. 1999. "Succinite and Some Other Fossil Resins in Poland and Europe (Deposits, Finds, Features and Differences in IRS)." Estudiosdel Museo de Ciencias Naturals de Alava 14 (2): 73-117.

[8] Azhhirevich, L. F., et al. 2000. Problems of 
Amber-Bearing Formations in Belarus. Edited by Moskvich, V. A. RUP “BELGEO”, Minsk, 144.

[9] Bogdasarov, M. A. 2010. Amber and Other Fossil Resins of Eurasia. Brest: BrSU, 263.

[10] Poinar, G. O. 1992. Life in Amber. Stanford: Stanford University Press, 350.

[11] Trofimov, V. S. 1974. Amber. M.: Nedra, 183.

[12] Pentegova, V. A., et al. 1987. Terpenoids of Conifers. Novosibirsk: Nauka, 97.

[13] Larsson, S. G. 1978. Baltic Amber-A Palaeobotanical Study, Entomograph No. 1. Klampenborg: Scandinavian Science Press, 123.

[14] Conwentz, H. 1890. Monographie der Baltischen Bernsteinbäume. Danzig, 151.

[15] Ivanov, L. A. 1961. Biological Bases of Turpentine Production in the USSR. M.; L.: Goslesbumizdat, 234.

[16] Kaptarenko-Chernousova, O. K. 1951. Kiev Horizon and Elements of Its Paleogeography. Kiev: Academy of Sciences of the UkrSSR, 98.

[17] Baranov, V. I. 1959. Stages of Development of Flora and Vegetation in the USSR in the Tertiary Period. M, 135.

[18] Bogdasarov, M. A. 2009. Fossil Resins of Northern Eurasia: Abstract of a Diss. ...Doct. of Geol. and Mineral. Sciences: 25.00.01. Belarus. Scientific-Research Geological Prospecting. Institute-Minsk, 46.

[19] Bachofen-Echt, A. 1949. Der Bernstein und seine Einschlüsse. Verhandl d. Zool.-Bot. Ges. Bd. 80. 123.

[20] Maidanovich, I. A., and Makarenko, D. Y. 1988. Geology and Genesis of Amber-Bearing Deposits of the Ukrainian Polissia. Kyiv: Naukova dumka, 84.

[21] Sinitsyn, V. M. 1965. Ancient Climates of Eurasia. Paleogene and Neogene. L., 345.

[22] Trofimov, V. S. 1973. "Amber and Classification of Fossil Resins.” Lithology and Mineral Resources (1): 100-6.

[23] Trofimov, V. S. 1980. “Amber or Fossil Resins?"
Lithology and Mineral Resources (2): 124-32.

[24] Schluter, T., and von Gnielinski, F. 1987. The East African Copal: Its Geologic, Stratigraphic, Palaeontologic Significance and Comparison with Other Fossil Resins of Similar Age. National Museum of Tanzania. Occasional paper No. 8, 32 .

[25] Tschirch, A., and Stock, E. 1933. Die Harze. Berlin.

[26] Krasnov, S. G., and Kaplan, A. A. 1976. "Stratigraphy, Lithology and Conditions for Formation of Amber-Bearing Deposits of the Paleogene in the Kaliningrad Region." Bulletin of the Mosc. S-ty of Naturalists. Geol. Depart. (2): 145-6.

[27] Savkevich, S. S. 1966. "On Conditions of Amber Formation." Report of the Academy of Sciences of the USSR. 168 (5): 162-5.

[28] Orlov, N. A., and Uspenskyi, V. A. 1936. Mineralogy of Caustobioliths. M.; L.: Academy of Sciences of the USSR, 198.

[29] Savkevich, S. S. 1973. "Amber and Amber-Bearing Fossil Resins of Ukraine." Theses of the Report at the 1st Uk. Lithol. Meeting, Kiev, 23-25 Oct. 1973. Institute of Geological Sciences of the Academy of Sciences of the UkrSSR, 116-7.

[30] Savkevich, S. S. 1980. "The New in the Mineralogical Study of Amber and Some Other Fossil Resins." Semi-Precious Stones: Materials of the 11th Congress of the International Mineralogical Association, Novosibirsk, 4-10 Sept. 1978. International Mineralogical Association, All-Union Mineralogical Society, 17-28.

[31] Trofimov, V. S. 1978. "Main Stages of Amber Formation and Principles of Its Classification." Proceedings of the Academy of Sciences of the USSR. Geol. ser. (2): 128-38.

[32] Kiyvlenko, E. Y., and Senkevich, N. N. 1976. Geology of Ornamental Stone Deposits. M.: Nedra, 280. 